\title{
Proton- and ammonium-sensing by histaminergic neurons controlling wakefulness
}

\author{
Yevgenij Yanovsky ${ }^{1+}$, Jeffrey M. Zigman ${ }^{2+}$, Anna Kernder ${ }^{1+}$, Alisa Bein ${ }^{1}$, Ichiro Sakata $^{2 \ddagger}$, \\ Sherri Osborne-Lawrence ${ }^{2}$, Helmut L. Haas ${ }^{1}$ and Olga A. Sergeeva ${ }^{1 *}$ \\ Medical Faculty, Molecular Neurophysiology, Heinrich-Heine University, Duesseldorf, Germany \\ ${ }^{2}$ Departments of Internal Medicine and Psychiatry, University of Texas Southwestern Medical Center, Dallas, TX, USA
}

Edited by:

Jian-Sheng Lin, INSERM and Claude

Bernard University, France

\section{Reviewed by:}

Ulrich Misgeld, Institut für

Physiologie und Pathophysiologie,

Germany

Ritchie Brown, Harvard Medical

School, USA

Urs Gerber, University of Zurich,

Switzerland

\section{*Correspondence}

Olga A. Sergeeva, Medical Faculty,

Molecular Neurophysiology,

Heinrich-Heine University, D-40204,

Duesseldorf, Germany.

e-mail: olga.sergeeva@uni-

duesseldorf.de

${ }^{+}$These authors contributed equally to this work.

${ }^{\ddagger}$ Present Address:

Division of Life Sciences, Graduate School of Science and Engineering, Saitama University, Saitama, Japan.
The histaminergic neurons in the tuberomamillary nucleus (TMN) of the posterior hypothalamus are involved in the control of arousal. These neurons are sensitive to hypercapnia as has been shown in experiments examining c-Fos expression, a marker for increased neuronal activity. We investigated the mechanisms through which TMN neurons respond to changes in extracellular levels of acid/ $/ \mathrm{CO}_{2}$. Recordings in rat brain slices revealed that acidification within the physiological range ( $\mathrm{pH}$ from 7.4 to 7.0), as well as ammonium chloride $(5 \mathrm{mM})$, excite histaminergic neurons. This excitation is significantly reduced by antagonists of type I metabotropic glutamate receptors and abolished by benzamil, an antagonist of acid-sensing ion channels (ASICs) and $\mathrm{Na}^{+} / \mathrm{Ca}^{2+}$ exchanger, or by ouabain which blocks $\mathrm{Na}^{+} / \mathrm{K}^{+}$ATPase. We detected variable combinations of 4 known types of ASICs in single TMN neurons, and observed activation of ASICs in single dissociated TMN neurons only at pH lower than 7.0. Thus, glutamate, which is known to be released by glial cells and orexinergic neurons, amplifies the acid/ $/ \mathrm{CO}_{2}$-induced activation of TMN neurons. This amplification demands the coordinated function of metabotropic glutamate receptors, $\mathrm{Na}^{+} / \mathrm{Ca}^{2+}$ exchanger and $\mathrm{Na}^{+} / \mathrm{K}^{+}$ATPase. We also developed a novel HDC-Cre transgenic reporter mouse line in which histaminergic TMN neurons can be visualized. In contrast to the rat, the mouse histaminergic neurons lacked the $\mathrm{pH}$ 7.0-induced excitation and displayed only a minimal response to the mGluR I agonist DHPG $(0.5 \mu \mathrm{M})$. On the other hand, ammonium-induced excitation was similar in mouse and rat. These results are relevant for the understanding of the neuronal mechanisms controlling acid/ $/ \mathrm{CO}_{2}$-induced arousal in hepatic encephalopathy and obstructive sleep apnoea. Moreover, the new HDC-Cre mouse model will be a useful tool for studying the physiological and pathophysiological roles of the histaminergic system.

Keywords: mGluR, histamine, HDC-Cre, waking, ASIC

\section{INTRODUCTION}

The mammalian brain depends on a constant supply of glucose and oxygen. Lack of either one of them rapidly leads to failure of neuronal function. Extracellular levels of $\mathrm{CO}_{2}$ change in response to alterations of blood oxygen levels and are fundamental physicochemical signals controlling breathing and wakefulness. However, the mechanisms connecting changes in extracellular $\mathrm{CO}_{2}$ to arousal are unclear.

Arousal-inducing systems are modulated, either directly or indirectly, in response to hypercapnia or acidification. For instance, serotonin neurons from the dorsal raphe respond to $\mathrm{CO}_{2}$ and genetic deletion of serotonin neurons abolishes the ventilatory response to hypercapnia (Corcoran et al., 2009; Buchanan and Richerson, 2010). Similarly, previous studies have shown that the orexin (hypocretin) neurons in the perifornical area of the posterior hypothalamus are highly sensitive to minor changes in the extracellular $\mathrm{pH}$ (Williams et al., 2007), displaying a $100 \%$ increase in firing rate in response to a 0.1 unit acidic shift. Furthermore, in wild type but not in orexin-deficient mice augmented ventilation is observed during the $2 \mathrm{~h}$ following a brief hypercapnia episode (Terada et al., 2008), implicating the orexin system in the ventilatory response.

The tuberomamillary nucleus (TMN) in the posterior hypothalamus contains the wake promoting histamine system, which provides a complementary and synergistic control of wakefulness together with the orexin neurons (Anaclet et al., 2009). The ventrolateral TMN group of neurons shows increased c-Fos expression indicating increased neuronal activity (Johnson et al., 2005) in response to hypercapnia and consistent with the increased arousal response. It is unclear however, whether $\mathrm{CO}_{2}$ or protons can directly affect TMN neurons or this is the consequence of a system response. In particular, it is possible that histaminergic neurons are excited indirectly via other arousal systems since they receive excitatory afferents from orexinergic neurons (Eriksson et al., 2001) in addition to inputs from other arousal centers of the brain (Haas and Panula, 2003; Haas et al., 2008).

Acid-induced excitation is a hallmark of chemosensing neurons (Williams et al., 2007) and contrasts with the majority of brain neurons which respond to acidification with a hyperpolarization. The cellular mechanisms underlying acid-induced 
excitation are diverse. In addition to direct activation of acidsensitive ion channels (ASICs), acidification or hypercapnia may cause ATP-release from astrocytes. In brainstem, ATP-activation of respiratory neurons through $\mathrm{P} 2 \mathrm{Y} 1$ receptors is a core event in the fundamental reflex controlling breathing (Gourine et al., 2010). In addition, some acid-sensing mechanisms can be activated by ammonium (Pidoplichko and Dani, 2006) and hyperammonemia leads to intracellular acidification (Kelly and Rose, 2010). In hepatic encephalopathy with ammonia as a main pathogenic factor, brain histamine concentration is increased (Lozeva et al., 2003).

This study investigates the role of the histaminergic system in acid/ $/ \mathrm{CO}_{2}$-sensing and characterizes the mechanisms involved. We focus in detail on the ventrolateral part of the TMN since it is located close to the brain surface and may contact the cerebrospinal fluid. The expression of possible effector systems in the ventrolateral and the medial subdivisions of TMN are compared. The action of $\mathrm{pH} 7.0$ is also compared with that of ammonium chloride at $5 \mathrm{mM}$. Despite similarity of time course and magnitude, we show that different mechanisms are involved in the effects of protons and ammonia. We identify glutamate acting through mGluR I as a mediator of acid-induced excitation in rats but not in mice.

\section{MATERIALS AND METHODS PATCH-CLAMP RECORDINGS FROM RAT OR MOUSE TMN NEURONS IN SLICES}

Housing of rats, mice, and all animal procedures were in accordance with the Animal Protection Law of the Federal Republic of Germany and European Union: EEC (86/609/EEC) directives. They obtained approval of the UTSW Medical Center Institutional Animal Care and Use Committee (Dallas, TX, USA). All efforts were made to reduce the number of animals used. Recordings from histaminergic neurons in male Wistar rat (22-26 day old) or mouse hypothalamic slices were performed as previously described (Chepkova et al., 2012; Yanovsky et al., 2011). Cell-attached recording was used to register action potential currents (Perkins, 2006). Visual identification of histaminergic neurons was confirmed at the end of experiments by application of the histamine 3 (H3) receptor agonist R- $\alpha$ methylhistamine $(0.2 \mu \mathrm{M})$ (Yanovsky et al., 2012) (in $\mathrm{mM}): \mathrm{KCl}$ 130, $\mathrm{NaCl} 10, \mathrm{MgCl}_{2}$ 2, $\mathrm{CaCl}_{2}$ 0.25, glucose 5, Hepes 5, MgATP 5, EGTA 10, Na-GTP 0.3, pH 7.3 adjusted with $1 \mathrm{M} \mathrm{KOH.}$ Temperature was held at $33 \pm 0.5^{\circ}$ if not mentioned otherwise. For gramicidin-perforated patch-clamp recording, (Akaike, 1996) pipettes (4.5-6.0 M $\Omega$ ) were tip-filled with (in $\mathrm{mM}$ ): K-gluconate 138, $\mathrm{KCl} 11$, Hepes $10, \mathrm{MgCl}_{2} 2, \mathrm{pH} 7.3$, and back-filled with the same solution containing $50 \mu \mathrm{g} / \mathrm{ml}$ of gramicidin (Sigma). Gramicidin was dissolved in dimethyl sulfoxide $(5 \mathrm{mg} / 0.1 \mathrm{ml})$, and then was diluted to the final concentration with recording solution. Gramicidin-perforated patch experiments were started when series resistance was below $100 \mathrm{M} \Omega$. After identification of neurons properties, the holding potential was set to $-50 \mathrm{mV}$. Voltage signals and synaptic currents were filtered at $3 \mathrm{kHz}$ with a four-pole Bessel filter, sampled at $10 \mathrm{kHz}$ using pCLAMP9 software (Axon Instruments, Union City, CA, USA), and stored on a PC for off-line analysis. Cells were discarded if their capacitance transients changed during recordings by more than $10 \%$. Solutions of different $\mathrm{pH}$ were applied for $7 \mathrm{~min}$ through the bath perfusion system. They were obtained by changing $\mathrm{NaHCO}_{3}$ concentrations in the basal recording solution according to the protocols of Jarolimek et al. (1990). Briefly, to achieve $\mathrm{pH} 6.8$ saturated with carbogen and heated to $33.5^{\circ} \mathrm{C}$ the control solution was supplemented with $5 \mathrm{mM} \mathrm{NaHCO}_{3}$; for $\mathrm{pH}$ $7.0 \pm 0.05$ with $9 \mathrm{mM} \mathrm{NaHCO}$, for $\mathrm{pH} 7.2 \pm 0.05$ with $14 \mathrm{mM}$ $\mathrm{NaHCO}_{3}$. Given variations of $\mathrm{pH}$ are averages of measurements done on different experimental days. The control recording solution (ACSF: artificial cerebrospinal fluid, $\mathrm{pH}$ 7.4) was composed of (in mM): $\mathrm{NaCl} 125, \mathrm{KCl} 3.7, \mathrm{CaCl}_{2} 1.0, \mathrm{MgCl}_{2} 1.0, \mathrm{NaH}_{2} \mathrm{PO} 4$ 1.3, $\mathrm{NaHCO}_{3} 25, \mathrm{D}$-glucose 10.

\section{ELECTROPHYSIOLOGY IN ACUTELY ISOLATED NEURONS FROM SLICES}

The TMN was dissected from posterior hypothalamic slices $(450 \mu \mathrm{m}$ thick) and incubation with papain in crude form $(0.3-0.5 \mathrm{mg} / \mathrm{ml})$ for $20-30 \mathrm{~min}$ at $37^{\circ} \mathrm{C}$. After rinsing the tissue was placed in a small volume of recording solution with the following composition (in $\mathrm{mM}$ ): $\mathrm{NaCl} 150, \mathrm{KCl} 3.7, \mathrm{CaCl}_{2} 2.0$, $\mathrm{MgCl}_{2}$ 2.0, HEPES 10, glucose 10 ( $\mathrm{pH} 7.4$ ). Cells were separated by gentle pipetting and placed in the recording chamber. TMN neurons were recorded and identified as previously described (Sergeeva et al., 2010; Yanovsky et al., 2012). Briefly, patch electrodes were sterilized by autoclaving and filled with the electrode solution for whole-cell recordings (in $\mathrm{mM}$ ): $\mathrm{KCl} 130, \mathrm{NaCl} 10$, $\mathrm{MgCl}_{2}$ 2, $\mathrm{CaCl}_{2}$ 0.25, glucose 5, Hepes 5, Mg-ATP 5, EGTA 10, Na-GTP 0.3, pH 7.3 adjusted with $1 \mathrm{M} \mathrm{KOH}$. The cells were voltage-clamped by an EPC-9 amplifier. The holding potential was $-50 \mathrm{mV}$. An acutely isolated cell was lifted into the major chute of the application system, where it was continuously perfused with the sterile control bath solution. Substances were applied through a glass capillary (application tube), $0.08 \mathrm{~mm}$ in diameter. All solutions flowed continuously, gravity-driven, at the same speed and lateral movements of the capillaries exposed a cell either to control- or test-solutions. Solutions with different $\mathrm{pH}$ were prepared by the addition of different amounts of $\mathrm{HCl}$ to the recording solution (see above). In some experiments solutions at $\mathrm{pH}<6.5$ contained $10 \mathrm{mM}$ MES [2-(N-morpholino) ethanesulfonic acid, Sigma] instead of HEPES. As the obtained $\mathrm{pH}_{50}$ did not differ between the two buffers data were pooled. To evaluate the proton sensitivity of the cells the mean of the peak current amplitude was fitted with a dose-response curve using the equation:

$$
y=\left[\mathrm{A} 1-\mathrm{A} 2 / 1+\left(x / x_{0}\right)^{p}\right]+\mathrm{A} 2,
$$

where $\mathrm{A} 1$ and $\mathrm{A} 2$ are the bottom and top asymptote, $x_{0}$ is the half-activation between $\mathrm{A} 1$ and $\mathrm{A} 2$ and $p$ is Hill's slope.

\section{ASIC-EXPRESSION ANALYSIS (SINGLE-CELL RT-PCR)}

Amplification of cDNAs encoding for histidine decarboxylase was performed as previously described (Sergeeva et al., 2002, 2005, 2010). The expected size of the amplification product was $457 \mathrm{bp}$. For the first amplification round of the ASIC family we used following degenerate primers Dglo: $5^{\prime}$-ccRatRaacaRBcccatctg$3^{\prime}$ and Dgup: 5'-agatYcacagYcagKMKgaRcc- $3^{\prime}$. In the second amplification round the primers varied for each ASICchannel: ASIC 1 up: 5'-cctagtggagaaagaccaggaata-3' was used 
in combination with Dglo (size of PCR product: 276bp.), ASIC 2 lo: $5^{\prime}$-ccttttctgccagtagaccga- $3^{\prime}$ was taken with Dgup (321 bp), ASIC 3 up: $5^{\prime}$-gggtgactgcaataccgcat- $3^{\prime}$ with ASIC 3 lo: $5^{\prime}$-tcattcgacagccacacttc- $3^{\prime}(164 \mathrm{bp})$ and ASIC $4 \mathrm{up}: 5^{\prime}$ gaacagcggctaacttatctgc- $3^{\prime}$ with ASIC 4 lo: $5^{\prime}$-catgggccctcagagccc$3^{\prime}$ (263 bp). For the analysis of ASIC1 splice variants (ASIC1a and ASIC1b) amplification was done with the following primers: ASIC1up: $5^{\prime}$-tccctgggectgctgctg- $3^{\prime}$ and ASIC1lo: 5'gtggccgcccatcttg- $3^{\prime}$ (size of PCR product for the ASIC 1b: $324 \mathrm{bp}$ and for the ASIC 1a: $360 \mathrm{bp}$ ). Digestion of ASIC1a with the restriction endonuclease Eco RI (Invitrogen) confirmed presence of both splice variants in cDNA derived from the trigeminal ganglion: undigested amplimer of $324 \mathrm{bp}$ size (ASIC1b) was seen together with ASICla restricted cDNA fragments of $210 \mathrm{bp}$ und $150 \mathrm{bp}$ size. Thin-walled PCR tubes contained a mixture of first strand cDNA template $(1-1.5 \mu \mathrm{l}), 10 \times$ PCR buffer, $10 \mathrm{pM}$ each of sense and antisense primer, $200 \mu \mathrm{M}$ of each dNTP and 2.5 units Taq polymerase. The final reaction volume was adjusted to $10 \mu \mathrm{l}$ with nuclease-free water (Promega, Mannheim, Germany). $\left(\mathrm{MgCl}_{2}\right)$ was $2.5 \mathrm{mM}$. Amplifications were performed on a thermal cycler (Perkin Elmer, GeneAmp 9600, Weiterstadt, Germany). In each round, 35 cycles of the following thermal programs were used: denaturation at $94^{\circ} \mathrm{C}$ for $48 \mathrm{~s}$, annealing at $50-53^{\circ} \mathrm{C}$ for $48 \mathrm{~s}$, and extension at $72^{\circ} \mathrm{C}$ for $1 \mathrm{~min}$. For the second amplification round, $1.1 \mu \mathrm{l}$ of the product of the first PCR was used as a template. The Taq enzyme, PCR buffer, $\mathrm{Mg}^{2+}$ solution, and four dNTPs were all purchased from Qiagen (Erkrath, Germany). All oligonucleotides were synthesized by MWG-Biotech (Ebersberg, Germany). Products were visualized by staining with ethidium bromide and analyzed by electrophoresis in 2\% agarose gels. Randomly selected PCR products were purified in water (PCR purification kit, Qiagen, Erkrath, Germany) and sequenced on an automatic sequencing machine (ABI, model 377, Weiterstadt, Germany). Comparison with corresponding GENBANK sequences revealed no mismatches (ASIC 1: NM_024154.2, ASIC 2: NM_012892.2, ASIC 3: NM_173135.1, ASIC 4: NM_022234.2).

\section{SEMIQUANTITATIVE REAL-TIME RT-PCR}

The TMN was dissected from hypothalamic slices and total cellular mRNA was isolated using an mRNA isolation kit (Pharmacia Biotech) according to the manufacturer's protocol. Total mRNA was eluted from the matrix with $30 \mu \mathrm{l}$ of RNase-free water. For the reverse-transcription $8 \mu \mathrm{l}$ of eluted mRNA was added to $7 \mu \mathrm{l}$ of reagents mixture prepared according to the protocol of the "first strand cDNA synthesis kit" (Pharmacia Biotech). After incubation for $1 \mathrm{~h}$ at $37^{\circ} \mathrm{C}$ the reverse transcription reaction was stopped by freezing at $-20^{\circ} \mathrm{C}$. The reverse-transcription reactions were not normalized to contain the equivalent amounts of total mRNA. The PCR was performed in a PE Biosystems GeneAmp 5700 sequence detection system using the SYBR green master mix kit. Each reaction contained $2.5 \mu \mathrm{l}$ of the $10 \mathrm{xSYBR}$ green buffer, $200 \mathrm{nM}$ dATP, dGTP, and dCTP and $400 \mathrm{nM}$ dUTP, $2 \mathrm{mM} \mathrm{MgCl} 2,0.25$ units of uracil N-glycosylase, 0.625 units of Amplitaq Gold DNA polymerase, $10 \mathrm{pM}$ forward and reverse primers, $5 \mu \mathrm{l}$ of 1:4 diluted cDNA, and water to $25 \mu \mathrm{l}$. All reactions were normalized to $\beta$-actin expression. Primers for the $\beta$-actin, peripherin and mGluR I cDNA amplification were published previously (Chepkova et al., 2009; Yanovsky et al., 2011). Primers for the HDC_CDNA amplification (Sergeeva et al., 2002) and for the ASIC-cDNAs were the same as those used in the second round of single-cell RT-PCR. Primers for the histamine $N$-methyl-transferase were: HNMT up: $5^{\prime}$-ttcttggcacaaggagaca$3^{\prime}$ and HNMT lo: $5^{\prime}$-gctaagagaccatggaaaaat $-3^{\prime}$. The reactions were performed in tubes with MicroAmp optical caps. The reactions were incubated at $50^{\circ} \mathrm{C}$ for 2 min to activate uracil $\mathrm{N}^{\prime}$-glycosylase and then for $10 \mathrm{~min}$ at $95^{\circ} \mathrm{C}$ to inactivate the uracil $\mathrm{N}^{\prime}$-glycosylase and activate the Amplitaq Gold polymerase followed by 40 cycles of $15 \mathrm{~s}$ at $95^{\circ} \mathrm{C}, 1 \mathrm{~min}$ at $60^{\circ} \mathrm{C}$. The PCR reactions were subjected to a heat dissociation protocol (PE Biosystems 5700 software). Following the final cycle of the PCR, the reactions were heatdenaturated over a $35^{\circ} \mathrm{C}$ temperature gradient at $0.03^{\circ} \mathrm{C} / \mathrm{s}$ from $60^{\circ} \mathrm{C}$ to $95^{\circ} \mathrm{C}$. Each PCR product showed a single peak in the denaturation curves. Standard curves for real-time PCR protocols with all primer-pairs obtained with sequential dilutions of one cDNA sample (till 1:64) were found optimal (linear regression coefficients were $>0.95)$. Semiquantitative analysis of target gene expression relative to the $\beta$-actin endogenous control was performed according to the " $2-\Delta \Delta \mathrm{Ct}$ " $(\Delta$ Fold $)$ method as described previously (Chepkova et al., 2009).

\section{GENERATION OF HDC-Cre BAC TRANSGENIC MICE AND HISTOCHEMICAL VALIDATION OF THE TRANSGENE EXPRESSION WITH THE HELP OF LacZ- OR Tmt-REPORTER MICE}

We generated several lines of transgenic mice that express cre recombinase (Cre) within histidine decarboxylase-expressing cells. These animals were made by first using various ET-cloning "recombineering" technologies (Lee et al., 2001; Muyrers et al., 2001); to construct an HDC-Cre transgene-containing bacterial artificial chromosome (BAC). The original HDC BAC (RP24141 N14), which was purchased from BACPAC Resources Center at Children's Hospital Oakland Research Institute, spanned the entire coding region of HDC and furthermore contained approximately $92.42 \mathrm{~kb}$ sequence upstream of the HDC start codon and approximately $13.91 \mathrm{~kb}$ sequence downstream of the HDC stop codon. This BAC was transformed into EL250 cells by electroporation. EL250 cells were provided by N. Copeland; they contain heat-inducible recE and recT recombinases for homologous recombination and arabinose-inducible Flp-recombinase for site-specific recombination at frt sites (Lee et al., 2001). Next, a DNA fragment containing the coding sequence of Cre recombinase followed by an SV40 polyadenylation (polyA) signal and a kanamycin resistance gene flanked by frt sites (FKF) was inserted into the HDC BAC, at the translational start site of HDC, by ET-cloning. The construction of the Cre-polyA-FKF cassette was described previously (Dhillon et al., 2006). This insertion resulted in the removal of $2194 \mathrm{bp}$ of the HDC gene (this included the latter portion of exon 1 and the first portion of exon 2-which encodes the first 47 amino acids of histidine decarboxylase-and the intervening intron 1). Finally, the kanamycin resistance gene was removed by arabinose induction of Flp-recombinase, and the Cre recombinase coding region was sequenced to ensure that no mutations had been introduced. The Cre-modified HDC BAC was submitted to the UTSW Medical 
Center Transgenic Core Facility for microinjection into pronuclei of fertilized one-cell stage embryos of C57Bl6/J mice. We were successful in generating multiple potential HDC-Cre founder mice, of which one was shown to contain the expected Cre expression and activity within the CNS. Oligonucleotide primers used to confirm the genotype of mice harboring the HDC-Cre transgenes were as follows: M249: 5' -CAGGGAGTGCACAGCACAGACAA$3^{\prime}$ and M247: 5'-TGCGAACCTCATCACTCGTTGCAT-3'. The mice used in this study were on a pure C57BL6/J genetic background. Animals were housed under $12 \mathrm{~h}$ of light/12 h of dark per day in a temperature-controlled environment. They were fed standard chow diet (details) and had free access to water.

For histological validation of Transgene expression, HDCCre mice were bred to Rosa26-lox-STOP-lox-lacZ reporter mice

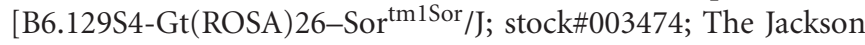
Laboratory, Bar Harbor, Maine], in which a transcriptional stop cassette is removed only in the presence of Cre activity, allowing for visualization of cells with Cre activity by assaying for $\beta$-galactosidase or for lacZ-IR, as below. Mice derived from the HDC-Cre X Rosa26-lox-STOP-lox-lacZ crosses were deeply anesthetized with an intraperitoneal injection of chloral hydrate $(500 \mathrm{mg} / \mathrm{kg})$ and subsequently perfused transcardially with diethylpyrocarbonate (DEPC)-treated $0.9 \%$ saline followed by $10 \%$ neutral buffered formalin. Brains were removed, stored in the same fixative for $4-6 \mathrm{~h}$ at $4^{\circ} \mathrm{C}$, and then immersed in $20 \%$ sucrose in DEPC-treated phosphate buffered saline (PBS), $\mathrm{pH} 7.0$ at $4^{\circ} \mathrm{C}$ overnight. Brains were sectioned coronally, using a sliding microtome, into five equal series at a $25 \mu \mathrm{m}$ thickness. Brain sections were permeabilized and blocked in 3\% normal goat serum $/ 0.3 \%$ Triton X-100 for $1 \mathrm{~h}$, and then incubated for $48 \mathrm{~h}$ at $4^{\circ} \mathrm{C}$ in 1:5000 guinea pig anti-HDC antiserum (Catalog number: B-GP 265-1, Lot: HS4061; ALPCO Diagnostics, Salem, NH). After washing in PBS, sections were incubated in Alexa Fluor 594 goat anti-guinea pig IgG (Invitrogen, Carlsbad, CA; 1:300) for $1 \mathrm{~h}$ at room temperature, followed by more PBS washes. For lacZ staining, sections were subsequently incubated for $24 \mathrm{~h}$ at $4^{\circ} \mathrm{C}$ in 1:10000 chicken anti-lacZ antiserum (Catalog number: ab9361, Lot: 713063, Abcam, Cambridge, MA). After washing in PBS, sections were incubated in Alexa Fluor 488 goat anti-chicken IgG (Invitrogen, Carlsbad, CA; 1:300) for $1 \mathrm{~h}$ at room temperature, followed by more PBS washes. Finally, the sections were mounted in Fluoromount G (Electron Microscopy Sciences, Hatfield, PA) and viewed using microscopy (Axioskop 2, Carl Zeiss). Images were taken using both the red filter and green filter at each level, and were placed side-by-side. All the cells at each level with either HDC-immunoreactivity alone, lacZ-immunoreactivity alone, or both were counted. An imaging editing software program, Adobe PhotoShop 7.0 (San Jose, CA) was used to adjust contrast, brightness, and color of the photomicrographs, and to merge the images taken using the red and green filters.

To be able to visualize TMN neurons in slices we crossed the HDC-Cre mouse to the Tomato reporter mouse $\mathrm{B} 6 \mathrm{~J} / \mathrm{N}$.

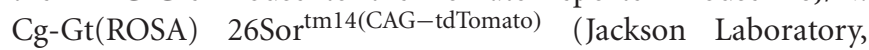
\#007908) yielding the HDC/Tmt mice. Offspring (both genders) carrying both transgenes were used for the slice recordings. Histamine immunostainings were done according to the previously published protocols (Yanovsky et al., 2011). Wilde type littermates of HDC-Cre breeders were used as a control in electrophysiological and molecular biological experiments (comparative gene expression analysis).

\section{DATA ANALYSIS}

Experiments were conducted and analyzed with commercially available software (TIDA for Windows, HEKA, Lambrecht, Germany) and with Clampex 9.0. All graphs were assembled in GraphPad Prism (GraphPad Software, Inc., San Diego, CA, USA) and Photoshop.

Data are presented in text as the mean \pm SEM. Statistical analysis was done with the non-parametrical Mann-Whitney $U$-test (real-time PCR) or unpaired Student $t$-test (comparison of magnitude of excitation between groups in cell-attached firing rate recordings). Comparison with the baseline activity in each individual experiment was done using paired Student $t$-test. Differences were considered statistically significant if $p<0.05$.

\section{RESULTS}

\section{ACSF ACIDIFICATION EXCITES RAT E2 TMN NEURONS}

As it was shown previously that only the ventrolateral TMN of the rat shows increased c-Fos expression in response to systemic hypercapnia (Johnson et al., 2005), we performed now patch-clamp recordings from ventrolateral TMN, which corresponds to the E2 group (Figure 1A). Acidification of the bath solution for $7 \mathrm{~min}$ increased the firing rate of most rat TMN neurons recorded in cell-attached mode (23 out of 28 neurons, $82 \%)$. Unresponsive neurons were not further investigated. On average $\mathrm{pH} 7.0$-induced excitation amounted to $166 \pm 15 \%$ of control firing rate $\left(n=23\right.$ at $\left.33^{\circ} \mathrm{C}\right)$. The mean firing rate in these experiments under control conditions was $1.14 \pm 0.05 \mathrm{~Hz}$ $(n=28)$. The excitatory response did not show a significant temperature-dependence: at room temperature it reached $157 \pm$ $40 \%$ of control $(n=6)$. The period of high initial excitation in response to the acidification was followed by a reduction of activity with subsequent suppression of activity below control level in the beginning of the washout period (Figure 1B). The response to pH 7.0 in perforated patch whole-cell voltage-clamp recordings (Vh $=-50 \mathrm{mV}$ ) perfectly matched the time course of responses seen in the cell-attached configuration (Figure 1C). The initial inward current of $22 \pm 7 \mathrm{pA}$ (starting after $1.9 \pm 0.3 \mathrm{~min}$, maximum after $4.6 \pm 0.6 \mathrm{~min}$ ) was followed by an outward current of $8.5 \pm 1.4 \mathrm{pA}(0.9 \pm 0.1 \mathrm{~min}$ after beginning the washout $)$ (Figure 1C3). Note a slight and delayed decrease in membrane resistance measured in parallel experiments $(180 \pm 10 \mathrm{M} \Omega$ versus $190 \pm 4 \mathrm{M} \Omega$ in control, $n=4, p>0.05)$, which did not correspond with respect to time to the fast rising phase of the inward current (Figure 1C4). Moreover, no robust membrane depolarisation was observed during the first phase of the response ( $n=5$, Figure 1C2), whereas the second phase was characterized by reduced firing frequency, outward current and membrane hyperpolarization. The magnitude of facilitation was dependent on the degree of acidification. The firing rate measured in cellattached configuration was changed by $17 \pm 2 \%$ for each $0.1 \mathrm{pH}$ unit (Figure 2A). 


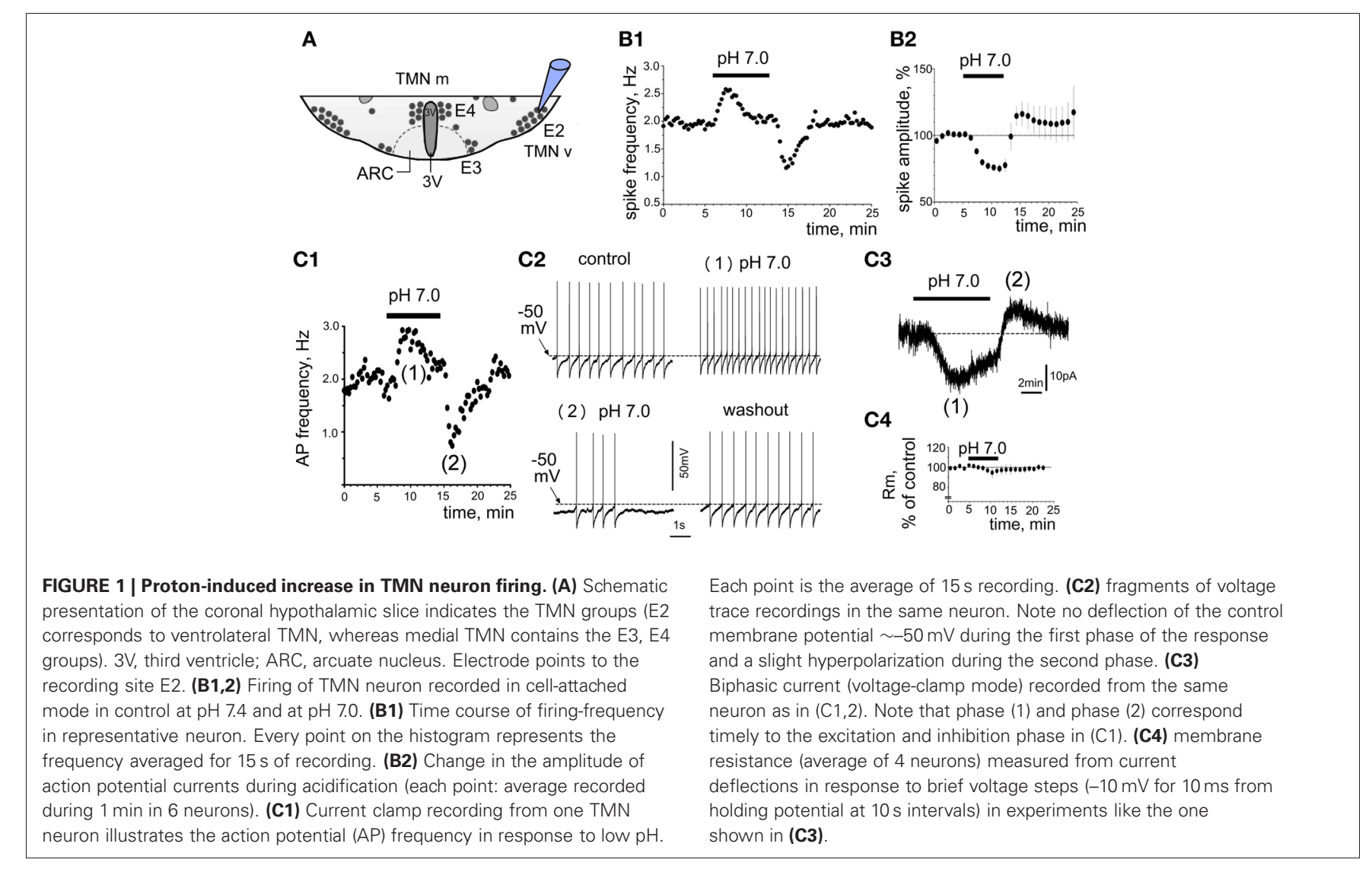

\section{METABOTROPIC GLUTAMATE RECEPTORS BUT NOT P2Y1 RECEPTORS MEDIATE ACID-INDUCED EXCITATION}

Previous studies have shown that glial cells respond to acid/ $/ \mathrm{CO}_{2}$ by the release of ATP, which excites respiratory neurons in brain stem through the P2Y1 receptor (Gourine et al., 2010). We have shown that ATP/ADP excites TMN neurons through P2X (Vorobjev et al., 2003) and P2Y (Sergeeva et al., 2006) receptors. We also found that activation of P2Y1 receptors in hypothalamic slices containing TMN causes release of glutamate which amplifies the excitatory response through type I metabotropic glutamate receptors (mGluR I). Acid-induced excitation of TMN neurons in the present study was not affected by the P2Y1 receptor antagonist MRS $2179(90 \mu \mathrm{M}, n=5$; Figure $2 B)$. The metabotropic glutamate receptor type I (mGluR I) antagonists MPEP $(10 \mu \mathrm{M}$, mGluR5 antagonist) combined with LY 367385 (20 $\mu \mathrm{M}$, mGluR1 antagonist) (Figure 2C) significantly reduced acid-induced excitation $(p<0.05)$. In the presence of mGluR I antagonists the excitation amounted to $123 \pm 10 \%(n=6)$ of baseline activity versus $211 \pm 31 \%(n=10)$ in the parallel control experiments. The AMPA and NMDA receptor antagonists CNQX $(10 \mu \mathrm{M})$ and D-AP5 $(50 \mu \mathrm{M})$ neither affected protoninduced excitation ( $199 \pm 30 \%, n=3$ ) nor increased the block of excitation by metabotropic glutamate receptor antagonists when all glutamate receptor antagonists were applied together $(138 \pm$ $28 \%$ of control, $n=4$, Figure $2 \mathrm{C}$ ). Thus proton-induced excitation is largely $(\sim 70 \%)$ mediated by metabotropic glutamate receptors.

\section{EXPRESSION OF ACID-SENSORS IN VENTROLATERAL VERSUS MEDIAL TMN}

Electrophysiological experiments revealed that mGluR mediate most of the acid-induced excitation of TMNv. Therefore, we investigated differential expression of these receptors with respect to functional diversity between $\mathrm{TMNv}$ and $\mathrm{TMNm}$ (Figure 2D). Semiquantitative RT-PCR was performed from mRNA isolated from two parts of TMN as shown in Figure 2D. The lateral part contained largely the E2 dense group of TMN neurons, whereas in the medial part only a minority of cells were histaminergic (groups E3 and E4, see Figure 1A). Therefore, histaminergic markers, such as histidine decarboxylase (HDC) or peripherin (prph) were expressed significantly higher in the ventrolateral part compared to the medial TMN (Figure 2D). Expression of mGluR1 did not differ between ventrolateral and medial TMN, whereas mGluR5 expression in the ventrolateral TMN represented $79 \%$ of that in the medial TMN $(p<0.05)$.

We then investigated the expression of classical acid-sensors, such as acid-sensing ion channels (ASICs) which others found expressed in the majority if not in all central neurons (Lingueglia, 2007; Grunder and Chen, 2010). We found the expression of ASIC3 significantly higher in ventrolateral TMN compared to the medial subdivision (Figure 2D). Interestingy, this member of the ASIC family responds to acidic $\mathrm{pH}$ with a fast inactivating followed by a sustained sodium current and is sensitive to physiological changes in proton concentration (Waldmann et al., 1997). 

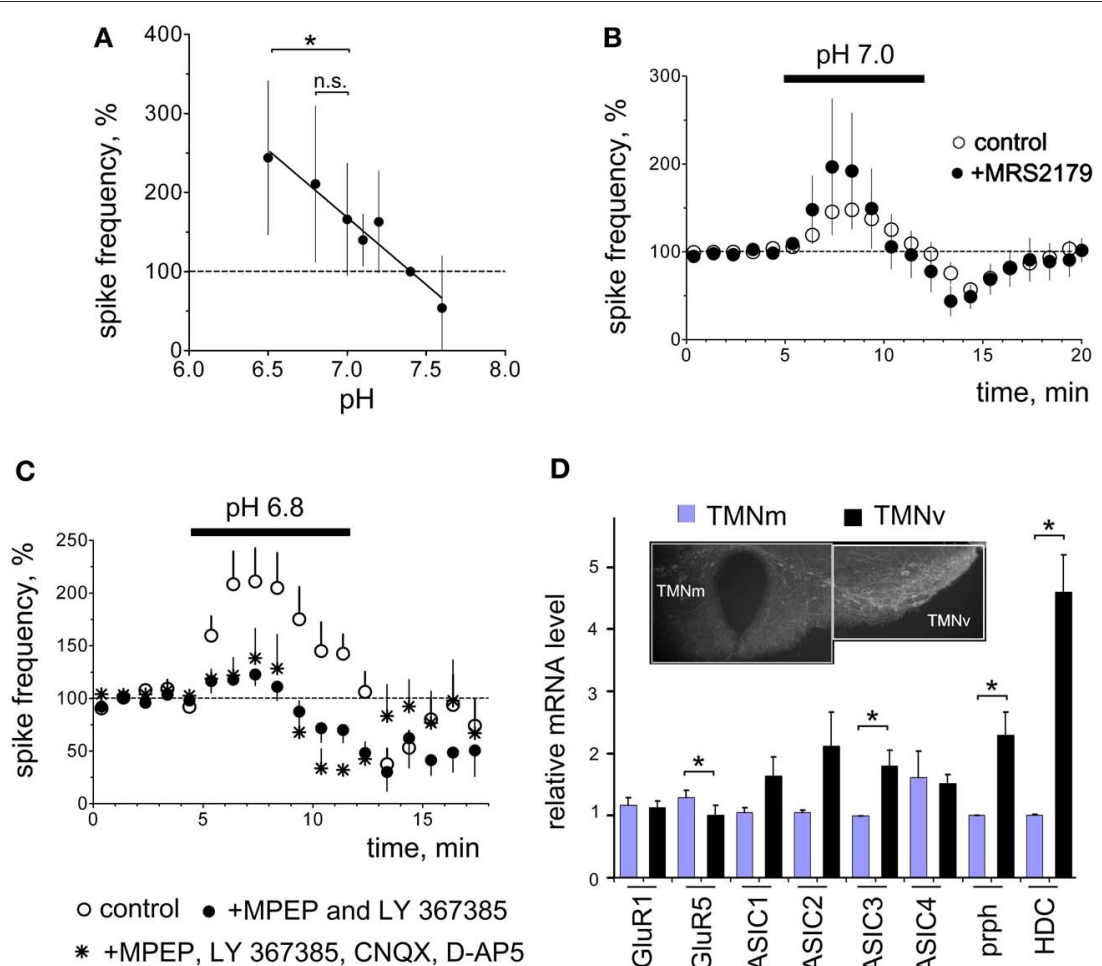

D

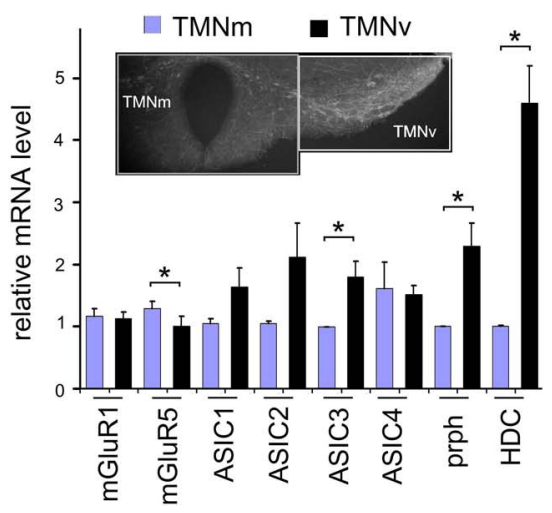

FIGURE 2 | Functional identification and expression analysis of acid-sensors in TMN. (A) Acid-induced excitation depends on the degree of acidification. Each data point is an average of 4-23 neurons. The difference in excitation between $\mathrm{pH} 6.5$ and 7.0 but not between $\mathrm{pH} 6.8$ and 7.0 is significant $(* p<0.05)$. (B) The P2Y1 receptor antagonist MRS2179 $(n=5)$ does not prevent pH 7.0-excitation. Control diagram represents the average of 23 neurons. (C) Facilitation of firing in control and in the presence of the metabotropic GluR (mGluR) antagonists MPEP (mGluR5, $10 \mu \mathrm{M}$ ) and LY367385 (mGluR1, $20 \mu \mathrm{M}$ ) or mGluR antagonists combined with inotropic

glutamate receptor antagonists $\mathrm{CNQX}(10 \mu \mathrm{M}, \mathrm{AMPA})$ and D-AP5 (50 $\mu \mathrm{M}$, NMDA). (D) mRNA levels normalized to the minimal expression level for mGluR1, mGluR5, ASIC (1-4), peripherin (prph) and histidine decarboxylase (HDC) detected with real-time RT-PCR (eight rats aged from 23 to 27 days). Hypothalamic slice shows regions dissected for the analysis. TMN neurons stained with the rabbit-anti-histamine antibody are visualized with the secondary donkey-anti-rabbit antibody conjugated to Alexa fluor 488 . ${ }^{*} p<0.05$ Mann-Whitney.

Expression of ASIC3 in the hypothalamus was shown recently (Meng et al., 2009). Members of ASIC 1 and ASIC2 subfamilies are activated by much lower $\mathrm{pH}$ values $\left(\mathrm{pH}_{50} \sim 4.1-6.2\right)$ except for ASIC 1a (Lingueglia, 2007), which also responds to ammonium (Pidoplichko and Dani, 2006).

\section{TMN NEURONS ISOLATED FROM SLICES DO NOT RESPOND TO pH 7.0}

Solutions with $\mathrm{pH}$ ranging from 7.0 to 4.0 were applied for $2 \mathrm{~s}$ at $30 \mathrm{~s}$ intervals in 17 acutely isolated TMN neurons. In none of the investigated neurons did $\mathrm{pH} 7.0$ evoke measurable currents, whereas pH 6.5 evoked currents of $37 \pm 8 \mathrm{pA}$ in $82 \%$ of neurons (Figure 3B). Half-maximal current amplitude was evoked by $\mathrm{pH} 5.8 \pm 0.1$. In 12 neurons a solution with $\mathrm{pH} 6.0$ was applied alone or in the presence of the ASIC blocker benzamil hydrochloride (bzm). Bzm $10 \mu \mathrm{M}$ suppressed the peak current amplitude to $59 \pm 8 \%$ of control $(n=4)$ without effects on plateau current. Bzm $20 \mu \mathrm{M}$ suppressed peak current to $30 \pm 6 \%$ and plateau to $57 \pm 11 \%$ of control $(n=12)$ (see Figure 3). The reversal potential of the acid-induced current was determined in 3 TMN neurons. Currents in response to acidic $\mathrm{pH}$ were inward at negative membrane potentials and became outward at potentials more positive than $+64 \pm 4 \mathrm{mV}$ (the predicted reversal potential for the sodium ion under our recording conditions is $+63.4 \mathrm{mV}$ ). Previous studies have shown that ASICs are mainly permeable for sodium ions (Bassilana et al., 1997; Waldmann et al., 1997). Single-cell RT-PCR analysis was performed from 32 TMN neurons. We found variable expression of all four known ASICs in histaminergic cells: thus ASIC1 transcripts were detected in $71 \%$, ASIC2 in 56\%, ASIC3 in $63 \%$ and ASIC 4 in $47 \%$ of TMN neurons $(n=32$, Figures 3C,D). Restriction analysis of PCR fragments containing the splice region of ASIC1 showed that only the ASIC1a subtype is expressed in TMN. The whole TMN region was analyzed from four rats. This result was confirmed by sequencing. Thus, similar to dopaminergic neurons of the midbrain (Pidoplichko and Dani, 2006) TMN neurons express ammonium-sensitive ASIC1a.

\section{$\mathrm{Na}^{+} / \mathrm{Ca}^{2+}$ EXCHANGE AND $\mathrm{Na}^{+} / \mathrm{K}^{+}$ATPase ARE ESSENTIAL FOR ACID-EVOKED TMN EXCITATION}

To test the participation of ASICs in the acid-induced excitation of TMN, we applied pH 7.0 in the presence of bzm $(20 \mu \mathrm{M}, n=3)$ and found that the firing increase was virtually abolished (Figure 4A). This can be explained by the 


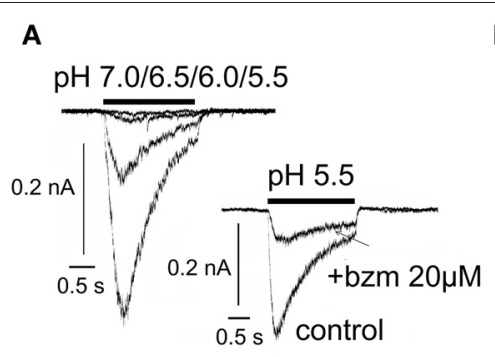

D

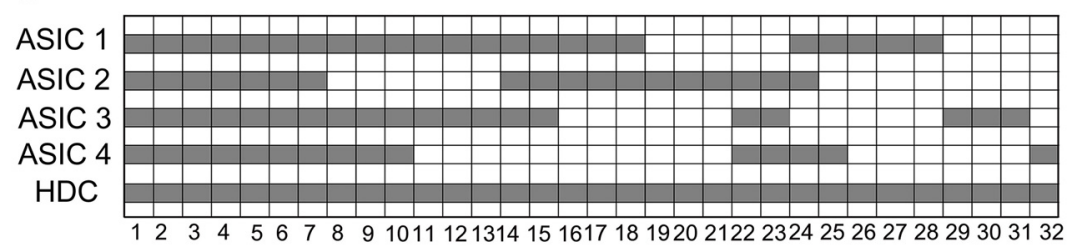

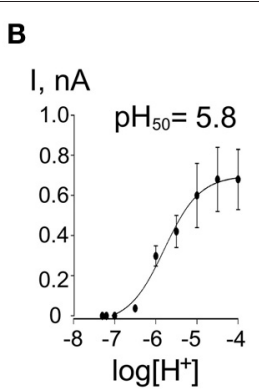

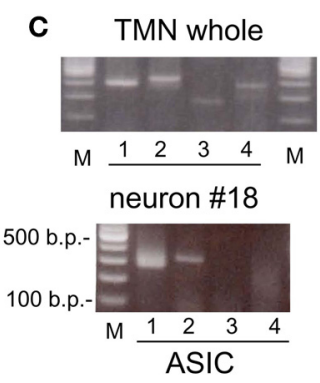

FIGURE 3 | Expression and function of ASIC (acid sensing ion channels) in TMN neurons. (A) Acid-induced currents in two representative neurons. Neurons are moved to the test solution with indicated $\mathrm{pH}$ for $2 \mathrm{~s}$ from the control ACSF (pH 7.4). Benzamil hydrochloride (bzm) abolishes the fast inactivating phase of the response and reduces the non-desensitizing component. (B) Averaged current-pH histogram represents data obtained from 17 neurons. Data points are fitted with the logistic equation. (C) Photographs of gels illustrate RT-PCR analysis of ASIC (1-4) expression in whole TMN and in one representative neuron. (D) Floating bar histograms show co-expression of 4 ASICs in 32 TMN neurons positive for histidine decarboxylase (HDC) simultaneous antagonism toward both: ASICs and $\mathrm{Na}^{+} / \mathrm{Ca}^{2+}$ exchange, which works in a reverse (depolarizing) mode downstream to mGluR activation. In addition, bzm blocks $\mathrm{Na}^{+} / \mathrm{H}^{+}$exchange, preventing intracellular acidification during exposure to acid.

Despite ubiquitous expression of ASICs in TMN neurons, the following findings argued against a massive ion flow through such membrane channels in response to $\mathrm{pH} 7.0$ and favor the idea that the sodium gradient is reduced during the excitation phase of the response, possibly through inhibition of $\mathrm{Na}^{+} / \mathrm{K}^{+}$ATPase by protons, as described previously for cardiomyocytes (Fuller et al., 2003): (1) lack of a pronounced membrane depolarisation during increased neuronal firing frequency; (2) decreased amplitude of action potential currents during the excitation phase; (3) no significant changes in $R_{\text {in }}$ seen in perforated patch configuration. Fuller et al. (2003) demonstrated that $\mathrm{Na}^{+} / \mathrm{K}^{+}$ATPase subtypes expressed in brain and heart are inhibited by a protonactivated factor during the initial phase of sodium influx in response to ischemia, which leads to membrane depolarisation. Increased intracellular sodium concentration turns on the $\mathrm{Na}^{+} / \mathrm{Ca}^{2+}$ exchange in the reverse mode leading to the extrusion of sodium, intracellular acidification and rise of calcium (Fuller et al., 2003). Therefore, the second, inhibitory phase of the response to acidification recruits calcium-activated potassium channels acting synergistically with the reverse electrogenic $\mathrm{Na}^{+} / \mathrm{Ca}^{2+}$ exchange ( 3 sodium ions are exchanged for 1 calcium ion) to produce a hyperpolarization. Upon return to the control ACSF ( $\mathrm{pH}$ 7.4) the $\mathrm{Na}^{+} / \mathrm{K}^{+}$ATPase regains its functionality and contributes to the hyperpolarization. This scenario, schematically depicted in Figure 4, could explain the biophysical characteristics of the first (excitatory) and second (inhibitory) phase of the TMN response to the mild (physiological) acidification. Indeed, $\mathrm{Na}^{+} / \mathrm{Ca}^{2+}$ exchange and $\mathrm{Na}^{+} / \mathrm{K}^{+}$ATPase were found to be essential for the first excitatory phase of the acid-induced excitation.

The $\mathrm{Na}^{+} / \mathrm{K}^{+}$ATPase blocker ouabain $(0.5 \mu \mathrm{M})$ increased the firing frequency of TMN neurons to $214 \pm 20 \%$ of control $(p<0.0001 ; n=8)$. In the presence of ouabain acidification of the extracellular solution produced neither excitation (Figure 4B) nor the rebound inhibition upon return to the control medium. When $\mathrm{pH}$ 7.0-induced currents were recorded in the presence of ouabain (perforated patch-clamp), outward currents were seen instead of inward currents in control experiments (Figure 4B). This can be explained by the activation of the reverse mode of $\mathrm{Na}^{+} / \mathrm{Ca}^{2+}$ exchange which leads, together with calcium-activated potassium currents to hyperpolarization.

\section{AMMONIUM-INDUCED EXCITATION DIFFERS FROM ACID-INDUCED EXCITATION OF TMN}

As ASICla responds to ammonium (Pidoplichko and Dani, 2006) we compared the pharmacology of ammonium-induced excitation with the acid-induced excitation in the following experiments. In cell-attached recordings $\mathrm{NH}_{4} \mathrm{Cl}$ evoked a transient increase in firing rate to $177 \pm 14 \%$ of control $(n=16)$. In some neurons an inhibition similar to that seen in experiments with $\mathrm{pH} 7.0$ was present at the beginning of the washout period (Figure 5). In contrast to the acidification-induced increase in firing rate, the excitation by ammonium was not prevented by mGluR I-antagonists $(n=4)$, by benzamil hydrochloride $(n=4)$ or by ouabain ( $n=3$, Figure 5$)$.

Ammonium can be transported instead of $\mathrm{K}^{+}$by the $\mathrm{Na}^{+} / \mathrm{K}^{+}$ ATPase (Kelly and Rose, 2010) or interact with KCC2 (potassium/chloride co-transporter) (Liu et al., 2003). Thus mechanisms of action of ammonium and of protons are different in TMN neurons. 


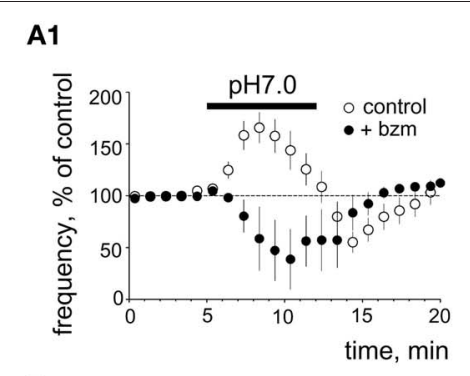

B

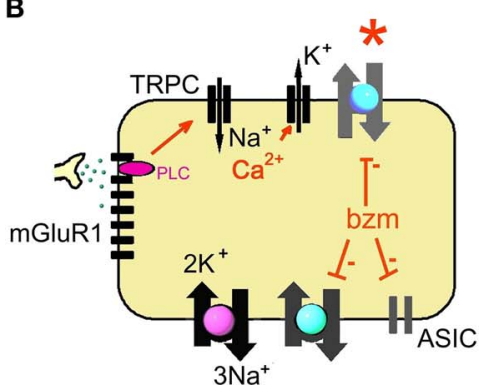

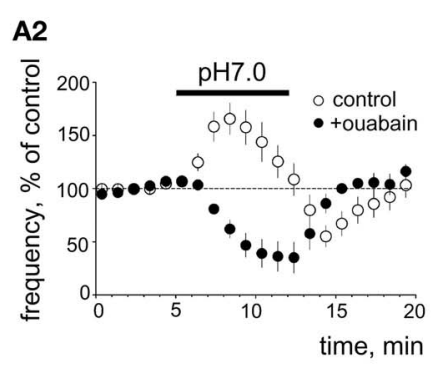

A3

C
FIGURE 4 | Benzamil or ouabain abolish acid-induced excitation.

(A1) Benzamil (bzm, $20 \mu \mathrm{M}$ ) blocks acid-induced excitation. (A2) Time course of firing frequency in control and in ouabain $(0.5 \mu \mathrm{M})$. (A3) gray trace shows acid-induced outward current recorded in ouabain (perforated patch-clamp mode) superimposed to the black (control) response recorded from the same neuron. (B,C) Models explaining action of bzm or ouabain. Bzm inhibits ASIC,

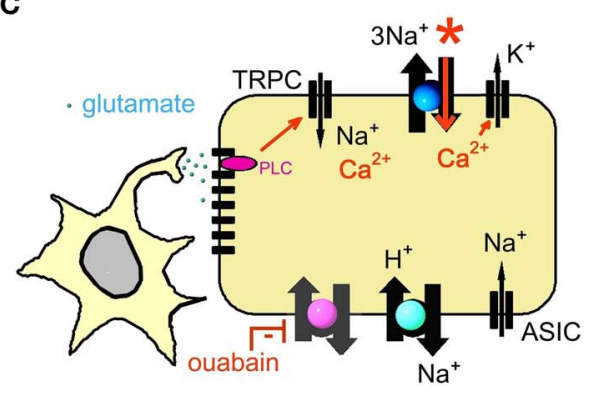

$\mathrm{Na}^{+} / \mathrm{H}^{+}$and $\mathrm{Na}^{+} / \mathrm{Ca}^{2+}$ exchangers. Ouabain (C) blocks $\mathrm{Na}^{+} / \mathrm{K}^{+}$ ATPase, which leads to the compensatory sodium removal by $\mathrm{Na}^{+} / \mathrm{H}^{+}$and $\mathrm{Na}^{+} / \mathrm{Ca}^{2+}$ exchangers, which is accompanied by a rise of intracellular $\mathrm{Ca}^{2+}$ and calcium-activated potassium conductance. Red stars point to block of the direct mode of $\mathrm{Na}^{+} / \mathrm{Ca}^{2+}$ exchange in both experimental sessions.

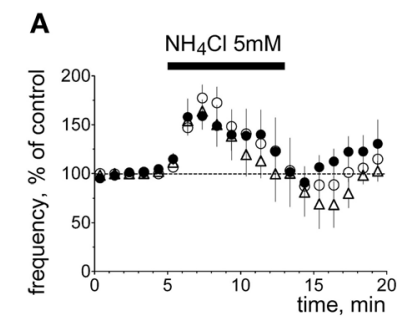

o control • bzm $\triangle$ MPEP + LY 367385

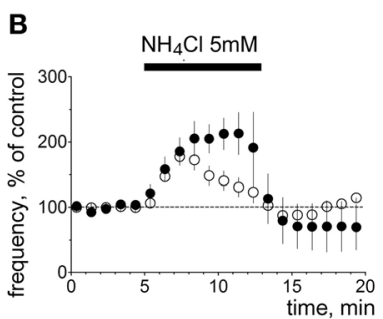

ocontrol $\bullet$ ouabain
FIGURE 5 | Ammonium-induced excitation. (A) Averaged time course diagrams show normalized firing frequency (cell-attached voltage-clamp mode) in control experiments and in the presence of indicated blockers, which abolish pH 7.0-induced excitation. (B) Ouabain does not block ammonium-induced excitation.

\section{ARE METABOTROPIC GLUTAMATE RECEPTORS ESSENTIAL FOR THE ACID-INDUCED EXCITATION? GENERATION AND CHARACTERIZATION OF HDC-Cre MICE}

Our experiments in rats showed that metabotropic glutamate receptors of type I, NCX and $\mathrm{Na}^{+} / \mathrm{K}^{+}$ATPase are the major players in proton-induced excitation of TMN, but not in response to ammonia. In order to identify the role of the histaminergic system in the response to hypercapnia or/and hyperammonemia it would be important to delete the major sensors only in histidine-decarboxylase (HDC) expressing neurons and see the behavioral response according to the previously published protocols (Johnson et al., 2005). For this purpose an HDC-Cre mouse was generated. A schematic diagram showing derivation of the HDC-Cre mouse is shown in Figure 6. In initial experiments a
Table 1 | Co-expression of Cre recombinase activity and HDC within the ventrolateral tuberomamillary nucleus of HDC-Cre transgenic line ${ }^{1}$.

\begin{tabular}{lll}
\hline $\begin{array}{l}\text { Approximate distance } \\
\text { of section to Bregma }\end{array}$ & $\begin{array}{l}\text { \% lacZ-IR } \\
\text { co-expressing HDC-IR }\end{array}$ & $\begin{array}{l}\text { \% HDC-IR neurons } \\
\text { co-expressing lacZ-IR }\end{array}$ \\
\hline$-2.30 \mathrm{~mm}$ & 100 & $76.3 \pm 2.9$ \\
$-2.70 \mathrm{~mm}$ & 100 & $71.1 \pm 2.5$ \\
$-2.92 \mathrm{~mm}$ & 100 & $75.7 \pm 2.9$ \\
\hline
\end{tabular}

${ }^{1}$ The percentage of HDC-IR/LacZ-IR co-expressing neurons was determined at three different levels through the ventrolateral tuberomamillary nucleus. The data are reported as the mean percentage \pm SEM for three different brains.

2 These approximate distances were determined by comparison to figures within the mouse brain atlas of (Paxinos and Franklin, 2004).

${ }^{3}$ lacZ-IR is a marker for the presence of Cre recombinase activity.

LacZ-reporter mouse was used for the visualization of HDC-Cre transgene in TMN. Results of this analysis are summarized in Table 1 and Figure 6.

For the electrophysiological recordings another reporter mouse was used which allowed us to visualize living TMN neurons in the slices. The co-localization pattern of transgene and histamine in the HDC/Tmt-mouse was similar qualitatively and quantitatively to that seen in the LacZ-reporter mouse. Thus, in the ventrolateral TMN (our recording site) all Tmt + neurons contained histamine (Figure 7A). Among 1101 histaminergic neurons counted in similar fields as shown in Figure 7A (21 fields in slices obtained from five mice were investigated) 298 neurons were negative for the Tmt-protein $(25.7 \pm 2.8 \%$ of total in each mouse $)$. 

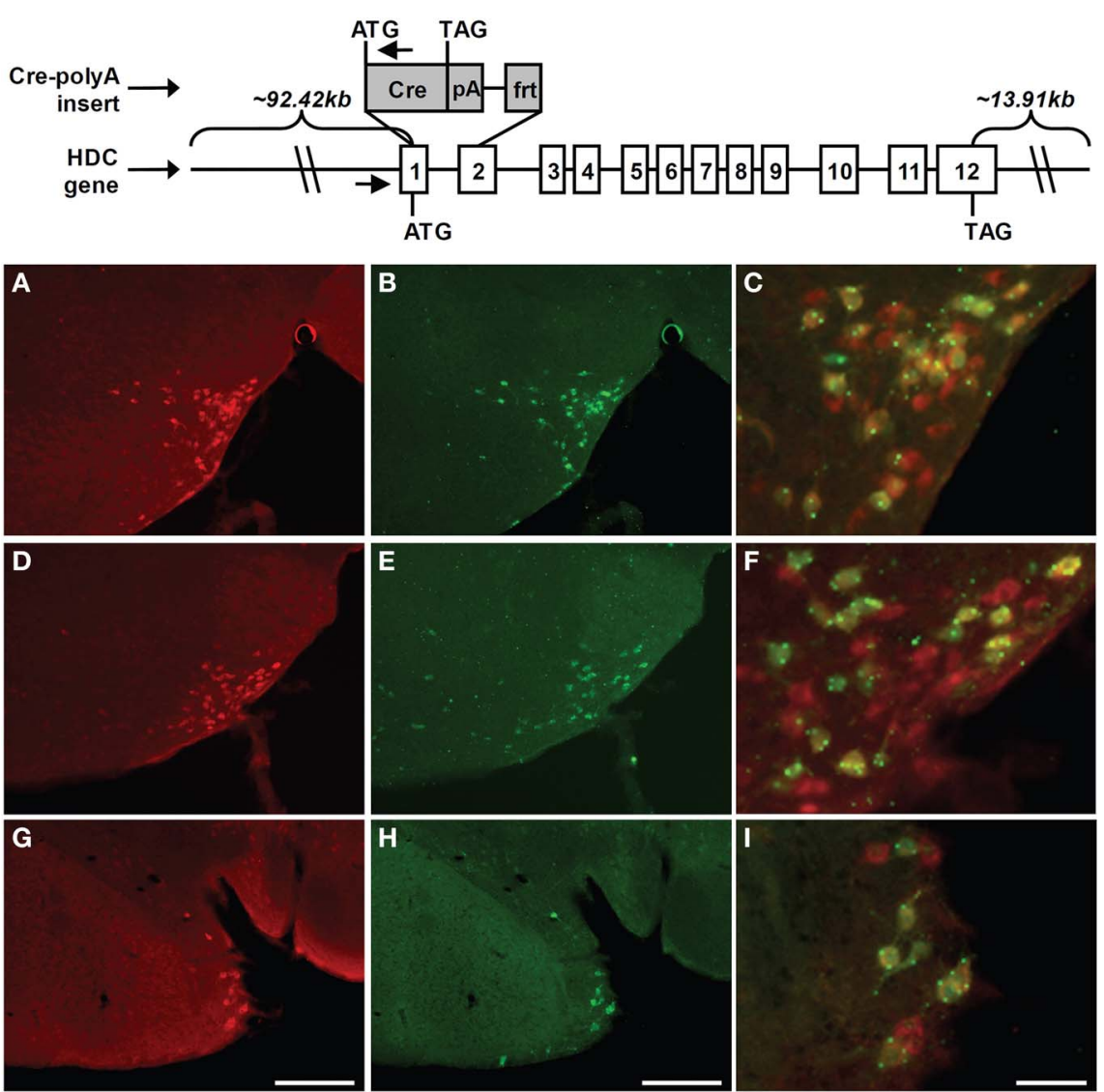

FIGURE 6 | Schematic diagram of the derivation of HDC-Cre transgenic mice and immunohistochemical analysis of transgene expression in TMN. Mice expressing Cre recombinase under the control of the HDC promoter were generated by inserting a Cre recombinase expression cassette into a BAC genomic clone containing HDC. In particular, a 2194-bp region of $\mathrm{HDC}$ was replaced by the coding sequence of Cre recombinase followed by an SV40 polyadenylation signal (pA) and an frt site. HDC's exons (denoted by numbered rectangles), and the start codons (ATG) and stop codons (TAG) for HDC and Cre are all indicated. The amounts of mouse chromosomal sequence present in the BAC either upstream of the HDC start codon or downstream of the HDC stop codon also are indicated. Small arrows denote the locations of oligonucleotide primers used for genotyping.
Expression of Cre activity within the tuberomamillary nucleus of the HDC-Cre transgenic mouse line was examined in coronal brain sections of Rosa26-lox-STOP-lox-lacZ reporter mice harboring the

HDC-Cre transgene. (A,D,G) Rostrocaudally arranged brain sections [(A) Bregma $-2.30 \mathrm{~mm}$, (D) Bregma $-2.70 \mathrm{~mm}$, (G) Bregma $-2.92 \mathrm{~mm}$ )] processed for HDC-immunoreactivity (red). (B,E,H) The same sections processed for lacZ-immunoreactivity (green). (C,F,I) Merged HDC (red) and lacZ signals (green), within cells containing co-localized HDC-and lacZ-immunoreactivity, appearing as yellow (yellow dots and green dots reflect highly localized collections of lacZ). Scale bars $=$ $200 \mu \mathrm{M}$ in $\mathbf{G}$ and $\mathbf{H}$ (applies to $\mathbf{A}, \mathbf{B}, \mathbf{D}, \mathbf{E}, \mathbf{G}, \mathbf{H}$ ); $50 \mu \mathrm{M}$ in I (applies to C, F, I).
The ventrolateral TMN (E2 group) in the mouse is not as compact as in the rat. Moreover, spontaneously firing cells in this region are not always histaminergic. Among 10 recorded cells in wild type (WT) mice $(n=3)$ only five reduced their firing activity in response to the histamine receptor 3 agonist R- $\alpha$-methylhistamine (RAMH, $2 \mu \mathrm{M}$ ) and were considered histaminergic neurons (Figure 7). All red (Tmt+) TMN neurons from HDC/Tmt mice responded to RAMH $(n=6)$ with an inhibition of firing not different from that seen in TMN neurons of WT mice (Figure 7B). Orexin A (100 nM) excited mouse TMN (Tmt + ) neurons to $255 \pm 63 \%$ of control frequency ( $n=4$, not shown) similar to our previous results in the rat (Eriksson et al., 2001).

Relative mRNA levels encoding for HDC, peripherin, histamine $N$-methyl-transferase (HNMT) and vesicular monoamine transporter (VMAT2) in the TMN region were found similar between WT and transgenic HDC/Tmt mice (Figure 7C). In contrast to the rat neither WT nor Tmt+ mouse TMN neurons were excited by $\mathrm{pH} 7.0$ (Figure 7D). Another difference was the significantly smaller excitation by the mGluR I agonist DHPG in mice (to $125 \pm 12 \%$ of control, $n=5$ ) compared to rats (to $220 \pm 26 \%$ of control $(n=5), p<0.05)$.

There was no difference between ammonium-induced excitation between rat and mouse TMN neurons: $177 \pm 14(n=16)$ and $240 \pm 42 \%(n=6)$ of control, respectively (Figure 8). Thus the HDC-Cre mouse offers a good model for exploring the role of the histaminergic system in hepatic encephalopathy, characterized by the hyperammonemia and increased histamine level in the brain (Lozeva et al., 2003). 

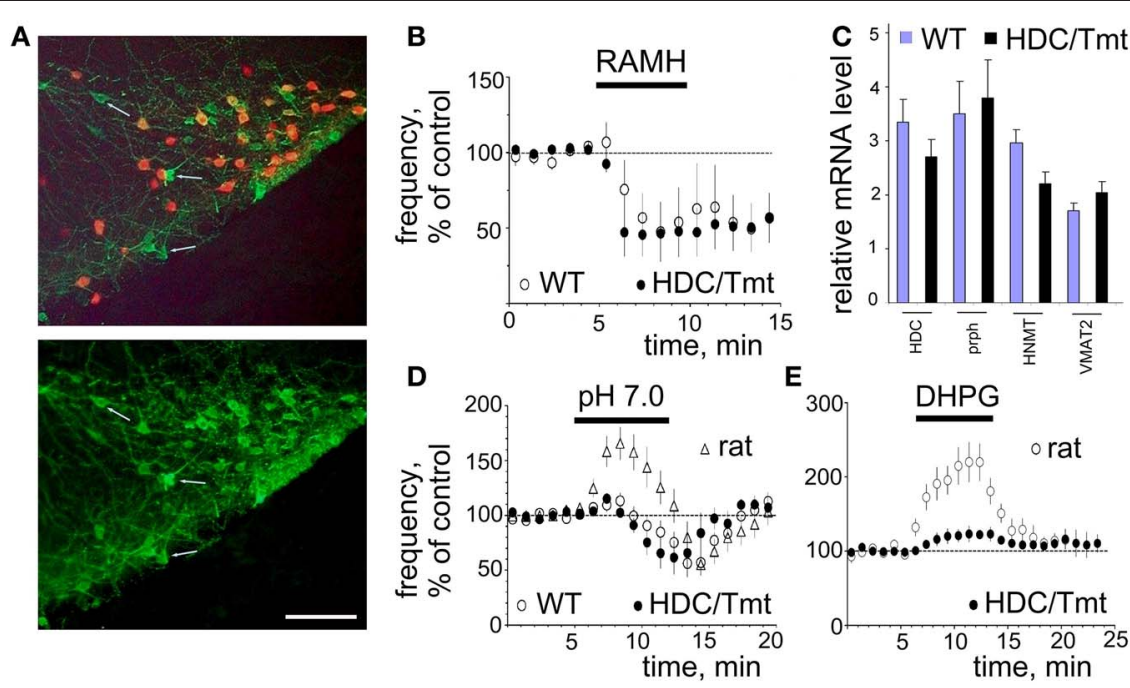

FIGURE 7 | Mouse TMN neurons resemble those of the rat but hardly respond to pH 7.0 and DHPG. (A) Histamine (AF488) co-localization with Tmt protein (expressed in HDC-Cre positive neurons). Note, that virtually all red cells are histamine-positive, but some histamine+ cells do not express HDC-Cre (few cells are indicated by arrows). Scale bar $100 \mu \mathrm{m}$. (B) The H3 receptor agonist $\mathrm{R}-(\alpha)$-methyl histamine $(\mathrm{RAMH}, 2 \mu \mathrm{M})$ similarly decreases firing rate of mouse WT $(n=5)$ and $\mathrm{Tmt}+(n=6) \mathrm{TMN}$ neurons. (C) Relative levels of mRNAs encoding for the markers of histaminergic activity in TMN region of 4 WT and $6 \mathrm{HDC} / \mathrm{Tmt}$ mice. HDC, histidine decarboxylase; prph, peripherin; HNMT, histamine N-methyl-transferase; VMAT2, vesicular monoamine transporter 2. (D) Acid-induced excitation is hardly seen in mouse WT $(n=6)$ or Tmt+ $(n=6)$ TMN neurons. Data points are superimposed to the time course diagram of acid-induced excitation from rats $(n=23)$. (E) The metabotropic glutamate receptor agonist DHPG $(0.5 \mu \mathrm{M})$ excites rat TMN neurons to a significantly larger extent $(n=5)$ than mouse TMN neurons $(n=5)$.
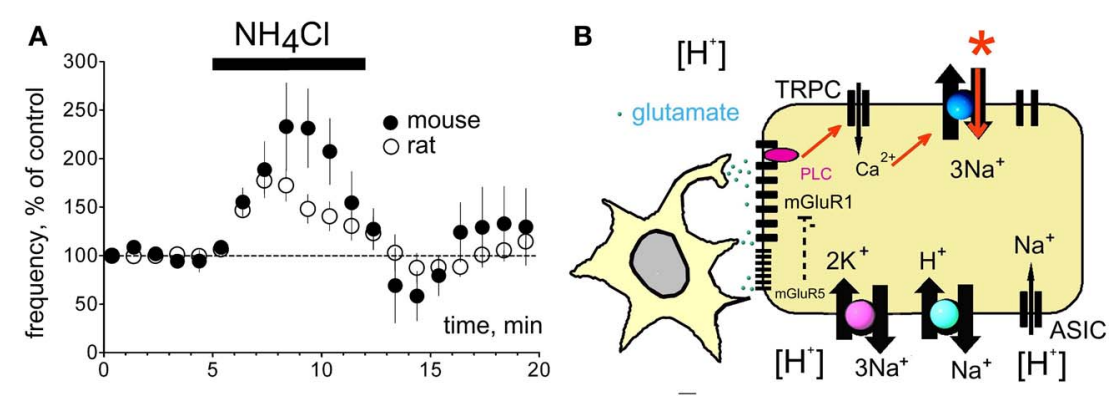

FIGURE 8 | Ammonium and proton-sensing in histaminergic TMN neurons. (A) Excitation by ammonium chloride (5 mM) is not significantly different between mouse and rat. None of the effectors depicted in (B) participates in ammonium-sensing. (B) Proton sensing cascade in TMN neuron, see discussion.

\section{DISCUSSION AND CONCLUSIONS}

The rat histaminergic neurons in the TMN respond to acidification in the physiological range ( $\mathrm{pH}$ 7.0) with an excitation resembling that of chemosensors in the brainstem. A similar effect has also been described for the neighboring orexin/hypocretin-containing neurons (Williams et al., 2007) which express glutamatergic markers (Torrealba et al., 2003). Optogenetic stimulation of their axons results in glutamatergic currents in some TMN neurons (Schöne et al., 2011), which may add to the acid-response of TMN neurons. In principle, ATP release from glia in response to acid $/ \mathrm{CO}_{2}$ could have excited TMN neurons, however antagonists at purinergic receptors failed to affect the excitation observed here.

We describe an unusually high sensitivity to glutamate of type I metabotropic receptors in TMN neurons. We applied the metabotropic glutamate receptor agonist DHPG at $0.5 \mu \mathrm{M}$, much below the concentrations used in previous studies $(50-200 \mu \mathrm{M}$, Bonsi et al., 2005; Hartmann et al., 2008; Chepkova et al., 2009). Mice lack the $\mathrm{pH}$ 7.0-induced excitation and show much smaller responses to DHPG compared to the rat.

Our previous single-cell RT-PCR analysis of mGluR I receptor expression in the rat TMN showed that almost all histaminergic neurons express mGluR1 but only $78 \%$ of them are mGluR5-positive (Sergeeva et al., 2006). The rat ventrolateral but not the medial TMN is activated by hypercapnia (Johnson et al., 2005). We show now a lower level of mGluR5 transcripts in this TMN part than in the non-responsive medial TMN. In striatal cholinergic neurons mGluR5 receptors mediate an increased desensitization rate of mGluR1 receptors (Bonsi et al., 2005), thus antagonizing the mGluR1-response. Although different effector systems are involved in mGluR I signaling in striatum and in TMN, such antagonistic interactions between mGluR5 and 
mGluR1 may provide an explanation for the lacking $\mathrm{pH} 7.0$ mediated excitation in the medial TMN with its higher expression level of mGluR5. Thus our current model explaining the protoninduced excitation of TMN (Figure 8B) depicts mGluR1 as a primary chain. The mGluR1 activates (through PLC) non-selective cation channels, most likely of the TRPC-type, which increase intracellular $\mathrm{Ca}^{2+}$. This is removed by the electrogenic $\mathrm{Na}^{+} / \mathrm{Ca}^{2+}$ exchanger (NCX) leading to depolarisation and increased firing. We have previously described NCX as the major effector for several excitatory neurotransmitters in TMN (Eriksson et al., 2004; Parmentier et al., 2009; Yanovsky et al., 2011). Block of ASIC, $\mathrm{Na}^{+} / \mathrm{H}^{+}$and $\mathrm{Na}^{+} / \mathrm{Ca}^{2+}$ exchangers by benzamil $(20 \mu \mathrm{M})$ also abolished the $\mathrm{pH}$ 7.0-induced excitation (Figure 4A), indicating that the direct mode of $\mathrm{Na}^{+} / \mathrm{Ca}^{2+}$ exchange is essential for the maintenance of low intracellular calcium level and for the neuronal excitation in response to $\mathrm{pH}$ 7.0. TMN neurons express variable types and splice variants of $\mathrm{Na}^{+} / \mathrm{Ca}^{2+}$ exchangers (NCX) (Sergeeva et al., 2003, 2004), their functional diversity remains to be elucidated. We have shown previously that serotonin, orexins/hypocretins, the dopamine receptor 2 agonist quinpirole and thyrotropin releasing hormone (TRH) excite TMN neurons by activation of NCX (Eriksson et al., 2004; Parmentier et al., 2009; Yanovsky et al., 2011). These transmitters are coupled to phospholipase C, like glutamate through type I metabotropic receptors (Wang et al., 2007), which are involved in acid-induced activation of TMN (see above). In our previous studies (Parmentier et al., 2009; Yanovsky et al., 2011) we found that non-selective cation channels (most likely of TRPC type) make the major contribution and are likely activated by the phospholipase C. Intracellular calcium rise allows sodium influx through the electrogenic (depolarizing) NCX. We did not observe pronounced depolarization in response to $\mathrm{pH} 7.0$ in the present study most likely due to the dissipation of sodium gradient and subsequent reversal of $\mathrm{Na}^{+} / \mathrm{Ca}^{2+}$ exchange.

Benzamil but not metabotropic glutamate receptor antagonists blocks proton-induced excitation entirely. Furthermore, acid-induced excitation does not disappear in TMN neurons in slices at room temperature, where NCX function is dramatically reduced (Eriksson et al., 2001; Parmentier et al., 2009). Therefore, we assume contributions from ASICs in $\mathrm{pH}$ 7.0-excitation, which is seen only in slices where a larger fraction of dendrites and axons is preserved than in the acutely isolated cells. Such a strategically important location of ASICs may have no impact on somatic membrane conductances but can influence local sodium concentrations and action potential generation. Dissipation of the sodium gradient after blockade of $\mathrm{Na}^{+} / \mathrm{K}^{+}$ ATPase may also abolish or reduce ASIC-currents. ASIC1a and ASIC3 are most likely candidates as they are highly sensitive to small, physiological changes in $\mathrm{pH}$ (Waldmann et al., 1997; Lingueglia, 2007). $\mathrm{Na}^{+} / \mathrm{K}^{+}$ATPase, $\mathrm{Na}^{+} / \mathrm{H}^{+}$exchanger and the direct mode of $\mathrm{Na}^{+} / \mathrm{Ca}^{2+}$ exchange play supportive roles for the $\mathrm{pH}$ 7.0-induced excitation maintaining sodium and calcium homeostasis. Impairment of their function abolishes the excitatory response, most likely by turning on the reverse mode of $\mathrm{Na}^{+} / \mathrm{Ca}^{2+}$ exchange, which leads to accumulation of intracellular calcium and recruits calcium-activated potassium channels. The inhibition of $\mathrm{Na}^{+} / \mathrm{K}^{+}$ATPase by protons (Fuller et al.,
2003) can contribute to the observed excitation of TMN. A block of this pump by ouabain $(0.5 \mu \mathrm{M})$ causes an acidification and an increase in firing rate comparable to that achieved by $\mathrm{pH}$ 7.0. The effects of ouabain and $\mathrm{pH} 7.0$ are not additive: acidification in the presence of ouabain does not produce an excitatory response, indicating that preservation of the sodium gradient under basal conditions is necessary for the excitatory response.

The mechanisms of proton- and ammonium-evoked excitation of the histaminergic neurons are different: blockers of the excitation by protons (ouabain, benzamil hydrochloride, antagonists of mGluRI) did not influence ammonium ( $5 \mathrm{mM}$ )-induced excitation. Moreover, ammonium-induced excitation did not differ between rat and mouse, whereas proton-induced excitation was only observed in rat, with the large DHPG $(0.5 \mu \mathrm{M})$ responses. As ammonium, similar to extracellular protons, causes intracellular acidification (Kelly and Rose, 2010) we believe that the increase in intracellular protons plays a role for both, acidand ammonium-sensing. We demonstrate now that blockade of proton entry into the cell $\left(\mathrm{Na}^{+} / \mathrm{H}^{+}\right.$exchanger $)$eliminates acidinduced excitation, but does not affect ammonium-induced excitation. Kelly and Rose (2010) have shown that ammonium enters hippocampal neurons through the $\mathrm{Na}^{+} / \mathrm{K}^{+}$ATPase, leading to intracellular acidification. We failed to block ammonium-induced excitation with the $\mathrm{Na}^{+} / \mathrm{K}^{+}$ATPase antagonist ouabain.

The novel HDC-Cre mouse presented here will provide unique possibilities to investigate physiological functions of the histaminergic system in normal and pathological brain. In particular, the role of the histaminergic system can be studied now under conditions of hyperammonemia, where it is poorly understood. In hepatic encephalopathy brain concentrations of histamine are elevated (Lozeva et al., 2003). The resulting changes in the histaminergic system are unknown; it could be protective or deleterious. Our recent experiments in histamine-deficient mice $\left(\mathrm{HDC}^{-/-}\right)$indicated that histamine may play a protective role against damaging effects of ammonia on hippocampal long-term potentiation (Chepkova et al., 2012).Thus, ammonium but not proton-induced excitation can be studied in transgenic mice which allow manipulating receptors and signaling cascades selectively in histaminergic neurons. This mouse will shed more light on the role of the histaminergic system in health and disease, for instance on obstructive sleep apnea and hepatic encephalopathy.

In conclusion, acidification excites the histaminergic neurons which are prominent keepers of the waking state. Physiological and pathophysiological changes of $\mathrm{pH}$ are thus bound to influence many functions of the hypothalamus including sleepwaking, energy homeostasis and the release of hormones.

\section{ACKNOWLEDGMENTS}

This work was supported by Deutsche Forschungsgemeinschaft (DFG) SE 1767/1(Heisenberg stipend to Olga A. Sergeeva) and SFB 575 C3 and C8 (to Olga A. Sergeeva and Helmut L. Haas). We wish to acknowledge Dr. Robert E. Hammer, director of the UTSW Transgenic Core Facility, for his assistance with the generation of the HDC-Cre mouse line, as well as Joel K. Elmquist for his technical support. This work was funded 
from the NIH (K08DK068069-01A2 to Jeffrey M. Zigman) and an International Research Alliance with The Novo Nordisk Foundation Center for Basic Metabolic Research (to

\section{REFERENCES}

Akaike, N. (1996). Gramicidin perforated patch recording and intracellular chloride activity in excitable cells. Prog. Biophys. Mol. Biol. 65, 251-264.

Anaclet, C., Parmentier, R., Ouk, K., Guidon, G., Buda, C., Sastre, J. P., Akaoka, H., Sergeeva, O. A., Yanagisawa, M., Ohtsu, H., Franco, P., Haas, H. L., and Lin, J. S. (2009). Orexin/hypocretin and histamine: distinct roles in the control of wakefulness demonstrated using knockout mouse models. J. Neurosci. 29, 14423-14438.

Bassilana, F., Champigny, G., Waldmann, R., de Weille, J. R., Heurteaux, C., and Lazdunski, M. (1997). The acid-sensitive ionic channel subunit ASIC and the mammalian degenerin MDEG form a heteromultimeric $\mathrm{H}^{+}$-gated $\mathrm{Na}^{+}$ channel with novel properties. J. Biol. Chem. 272, 28819-28822.

Bonsi, P., Cuomo, D., De Persis, C., Centonze, D., Bernardi, G., Calabresi, P., and Pisani, A. (2005). Modulatory action of metabotropic glutamate receptor (mGluR) 5 on mGluRl function in striatal cholinergic interneurons. Neuropharmacology 49 (Suppl. 1), 104-113.

Buchanan, G. F., and Richerson, G. B. (2010). Central serotonin neurons are required for arousal to $\mathrm{CO}_{2}$. Proc. Natl. Acad. Sci. U.S.A. 107, 16354-16359.

Chepkova, A., Yanovsky, E., Parmentier, R., Ohtsu, H., Haas, H. L., Lin, J. S., and Sergeeva, O. A. (2012). Histamine receptor expression, hippocampal plasticity and ammonia in histidine decarboxylase knockout mice. Cell. Mol. Neurobiol. 32, $17-25$.

Chepkova, A. N., Fleischer, W., Kazmierczak, T., Doreulee, N., Haas, H. L., and Sergeeva, O. A. (2009). Developmental alterations of DHPG-induced longterm depression of corticostriatal synaptic transmission: switch from NMDA receptor-dependent towards CB1 receptor-dependent plasticity. Pflugers Arch. 459, 131-141.

Corcoran, A. E., Hodges, M. R., Wu, Y., Wang, W., Wylie, C. J., Deneris, E. S., and Richerson, G. B. (2009). Medullary serotonin neurons and central $\mathrm{CO}_{2}$ chemoreception. Respir. Physiol. Neurobiol. 168, 49-58.
Dhillon, H., Zigman, J. M., Ye, C., Lee, C. E., McGovern, R. A., Tang, V., Kenny, C. D., Christiansen, L. M., White, R. D., Edelstein, E. A., Coppari, R., Balthasar, N., Cowley, M. A., Chua, S. Jr., Elmquist, J. K., and Lowell, B. B. (2006). Leptin directly activates SF1 neurons in the $\mathrm{VMH}$, and this action by leptin is required for normal bodyweight homeostasis. Neuron 49, 191-203.

Eriksson, K. S., Sergeeva, O. A., Selbach, O., and Haas, H. L. (2004). Orexin (hypocretin)/dynorphin neurons control GABAergic inputs to tuberomammillary neurons. Eur. J. Neurosci. 19, 1278-1284.

Eriksson, K. S., Stevens, D. R., and Haas, H. L. (2001). Serotonin excites tuberomammillary neurons by activation of $\mathrm{Na}(+) / \mathrm{Ca}(2+)$-exchange. Neuropharmacology 40, 345-351.

Fuller, W., Parmar, V., Eaton, P., Bell, J. R., and Shattock, M. J. (2003). Cardiac ischemia causes inhibition of the $\mathrm{Na} / \mathrm{K}$ ATPase by a labile cytosolic compound whose production is linked to oxidant stress. Cardiovasc. Res. 57, 1044-1051.

Gourine, A. V., Kasymov, V., Marina, N., Tang, F., Figueiredo, M. F., Lane, S., Teschemacher, A. G., Spyer, K. M., Deisseroth, K., and Kasparov, S. (2010). Astrocytes control breathing through $\mathrm{pH}$-dependent release of ATP. Science 329, 571-575.

Grunder, S., and Chen, X. (2010). Structure, function, and pharmacology of acid-sensing ion channels (ASICs): focus on ASICla. Int. J. Physiol. Pathophysiol. Pharmacol. 2, 73-94.

Haas, H., and Panula, P. (2003). The role of histamine and the tuberomamillary nucleus in the nervous system. Nat. Rev. Neurosci. 4, 121-130.

Haas, H. L., Sergeeva, O. A., and Selbach, O. (2008). Histamine in the nervous system. Physiol. Rev. 88 , 1183-1241.

Hartmann, J., Dragicevic, E., Adelsberger, H., Henning, $H$. A., Sumser, M., Abramowitz, J., Blum, R., Dietrich, A., Freichel, M., Flockerzi, V., Birnbaumer, L., and Konnerth, A. (2008). TRPC3 channels are required for synaptic transmission and motor coordination. Neuron 59, 392-398.

Jarolimek, W., Misgeld, U., and Lux, H. D. (1990). Neurons sensitive to $\mathrm{pH}$ in slices of the rat ventral

Jeffrey M. Zigman). We acknowledge Forschungskomission of Heinrich-Heine University Düsseldorf for the stipend to Anna Kernder.

medulla oblongata. Pflugers Arch. 416, 247-253.

Johnson, P. L., Moratalla, R., Lightman, S. L., and Lowry, C. A. (2005). Are tuberomammillary histaminergic neurons involved in $\mathrm{CO}_{2}$ mediated arousal? Exp. Neurol. 193 228-233.

Kelly, T., and Rose, C. R. (2010). Ammonium influx pathways into astrocytes and neurones of hippocampal slices. J. Neurochem. 115, 1123-1136.

Lee, E. C., Yu, D., Martinez de V., Tessarollo, L., Swing, D. A., Court, D. L., Jenkins, N. A., and Copeland, N. G. (2001). A highly efficient Escherichia coli-based chromosome engineering system adapted for recombinogenic targeting and subcloning of BAC DNA. Genomics $73,56-65$.

Lingueglia, E. (2007). Acid-sensing ion channels in sensory perception. $J$. Biol. Chem. 282, 17325-17329.

Liu, X., Titz, S., Lewen, A., and Misgeld, U. (2003). KCC2 mediates $\mathrm{NH}^{4+}$ uptake in cultured rat brain neurons. J. Neurophysiol. 90, 2785-2790.

Lozeva, V., Tuomisto, L., Tarhanen, J., and Butterworth, R. F. (2003). Increased concentrations of histamine and its metabolite, tele-methylhistamine and downregulation of histamine $\mathrm{H} 3$ receptor sites in autopsied brain tissue from cirrhotic patients who died in hepatic coma. J. Hepatol. 39, 522-527.

Meng, Q. Y., Wang, W., Chen, X. N., Xu, T. L., and Zhou, J. N. (2009). Distribution of acid-sensing ion channel 3 in the rat hypothalamus. Neuroscience 159, 1126-1134.

Muyrers, J. P., Zhang, Y., and Stewart, A. F. (2001). Techniques: recombinogenic engineering-new options for cloning and manipulating DNA. Trends Biochem. Sci. 26, 325-331.

Parmentier, R., Kolbaev, S., Klyuch, B. P., Vandael, D., Lin, J. S., Selbach, O., Haas, H. L., and Sergeeva, O. A. (2009). Excitation of histaminergic tuberomamillary neurons by thyrotropin-releasing hormone. J. Neurosci. 29, 4471-4483.

Paxinos, G., and Franklin, K. B. J. (2004). The Mouse Brain in Stereotaxic Coordinates: Compact, Second Edn. San Diego, CA: Academic Press.

Perkins, K. L. (2006). Cell-attached voltage-clamp and current-clamp recording and stimulation techniques in brain slices. J. Neurosci. Methods 154, 1-18.

Pidoplichko, V. I., and Dani, J. A. (2006). Acid-sensitive ionic channels in midbrain dopamine neurons are sensitive to ammonium, which may contribute to hyperammonemia damage. Proc. Natl. Acad. Sci. U.S.A. 103, 11376-11380.

Schöne, C., Apergis-Schoute, J., and Burdakov, D. (2011). Optogenetic Probing of Synaptic Transmission Between Orexin/Hypocretin and Histamine Neurons. SFN meeting, Washington, DC:Abstract.

Sergeeva, O. A., Amberger, B. T., Eriksson, K. S., Scherer, A., and Haas, H. L. (2003). Co-ordinated expression of 5-HT2C receptors with the NCX1 Na ${ }^{+} / \mathrm{Ca}^{2+}$ exchanger in histaminergic neurones. J. Neurochem. 87, 657-664.

Sergeeva, O. A., Amberger, B. T., Vorobjev, V. S., Eriksson, K. S., and Haas, H. L. (2004). AMPA receptor properties and coexpression with sodium-calcium exchangers in rat hypothalamic neurons. Eur. J. Neurosci. 19, 957-965.

Sergeeva, O. A., Andreeva, N., Garret, M., Scherer, A., and Haas, H. L. (2005). Pharmacological properties of GABAA receptors in rat hypothalamic neurons expressing the epsilon-subunit. J. Neurosci. 25, 88-95.

Sergeeva, O. A., Eriksson, K. S., Sharonova, I. N., Vorobjev, V. S., and Haas, H. L. (2002). GABA(A) receptor heterogeneity in histaminergic neurons. Eur. J. Neurosci. 16, 1472-1482.

Sergeeva, O. A., Kletke, O., Kragler, A., Poppek, A., Fleischer, W., Schubring, S. R., Gorg, B., Haas, H. L., Zhu, X. R., Lubbert, H., Gisselmann, G., and Hatt, H. (2010). Fragrant dioxane derivatives identify $\beta 1$-subunit-containing GABAA receptors. J. Biol. Chem. 285, 23985-23993.

Sergeeva, O. A., Klyuch, B. P., Fleischer, W., Eriksson, K. S., Korotkova, T. M., Siebler, M., and Haas, H. L. (2006). P2Y receptormediated excitation in the posterior hypothalamus. Eur. J. Neurosci. 24, 1413-1426.

Terada, J., Nakamura, A., Zhang, W., Yanagisawa, M., Kuriyama, T., Fukuda, Y., and Kuwaki, T. (2008). Ventilatory long-term facilitation 
in mice can be observed during both sleep and wake periods and depends on orexin. J. Appl. Physiol. 104, 499-507.

Torrealba, F., Yanagisawa, M., and Saper, C. B. (2003). Colocalization of orexin a and glutamate immunoreactivity in axon terminals in the tuberomammillary nucleus in rats. Neuroscience 119, 1033-1044.

Vorobjev, V. S., Sharonova, I. N., Haas, H. L., and Sergeeva, O. A. (2003). Expression and function of $\mathrm{P} 2 \mathrm{X}$ purinoceptors in rat histaminergic neurons. Br. J. Pharmacol. 138, 1013-1019.

Waldmann, R., Bassilana, F., de Weille, J., Champigny, G., Heurteaux, C., and Lazdunski, M. (1997).
Molecular cloning of a noninactivating proton-gated $\mathrm{Na}^{+}$ channel specific for sensory neurons. J. Biol. Chem. 272, 20975-20978.

Wang, M., Bianchi, R., Chuang, S. C., Zhao, W., and Wong, R. K. (2007). Group I metabotropic glutamate receptor-dependent TRPC channel trafficking in hippocampal neurons. J. Neurochem. 101, 411-421.

Williams, R. H., Jensen, L. T., Verkhratsky, A., Fugger, L., and Burdakov, D. (2007). Control of hypothalamic orexin neurons by acid and $\mathrm{CO}_{2}$. Proc. Natl. Acad. Sci. U.S.A. 104, 10685-10690.

Yanovsky, Y., Li, S., Klyuch, B. P., Yao, Q., Blandina, P., Passani, M. B., Lin,
J. S., Haas, H. L., and Sergeeva, O. A. (2011). L-Dopa activates histaminergic neurons. J. Physiol. 589, 1349-1366.

Yanovsky, Y., Schubring, S., Fleischer, W., Gisselmann, G., Zhu, X. R. Lubbert, H., Hatt, H., Rudolph, U., Haas, H. L., and Sergeeva, O A. (2012). $\operatorname{GABA}(\mathrm{A})$ receptors involved in sleep and anaesthesia: beta1- versus beta3-containing assemblies. Pflugers Arch. 463, 187-199.

Conflict of Interest Statement: The authors declare that the research was conducted in the absence of any commercial or financial relationships that could be construed as a potential conflict of interest.
Received: 16 January 2012; accepted: 21 March 2012; published online: 13 Apri 2012.

Citation: Yanovsky Y, Zigman JM, Kernder A, Bein A, Sakata I, OsborneLawrence S, Haas HL and Sergeeva OA (2012) Proton- and ammonium-sensing by histaminergic neurons controlling wakefulness. Front. Syst. Neurosci. 6:23. doi: 10.3389/fnsys.2012.00023

Copyright (C) 2012 Yanovsky, Zigman, Kernder, Bein, Sakata, OsborneLawrence, Haas and Sergeeva. This is an open-access article distributed under the terms of the Creative Commons Attribution Non Commercial License, which permits non-commercial use, distribution, and reproduction in other forums, provided the original authors and source are credited. 